\title{
EL DERECHO A LA SALUD NO ENTIENDE DE TIEMPOS
}

\section{THE RIGHT TO HEALTH DOES NOT UNDERSTAND TIMES}

\section{Nadia Virginia Copello ${ }^{1}$}

DOI: https://doi.org/10.37767/2591-3476(2021)19

\author{
Comentario a \\ MONTEVERDE, SABRINA SOFIA C/ ADMINISTRACION PROVINCIAL DEL SEGURO \\ DE SALUD (APROSS) \\ Cámara Contencioso Administrativa de $2^{\circ}$ Nominación \\ Poder Judicial de Córdoba
}

\author{
Disponible en \\ https://bit.ly/2WtLYxW
}

\section{RESUMEN:}

La justicia de la provincia de Córdoba hizo lugar al pedido de una medida cautelar autorizando el $100 \%$ de la cobertura del medicamento TRIKAFTA para el tratamiento de fibrosis quística. Se trata de una joven, Sabrina Monteverde, quien padece esta enfermedad poco frecuente y que dado el estado grave de salud que atraviesa, debió iniciar una acción de amparo contra Apross.

Si bien, no es el primer caso de un paciente que requiere la medicación mencionada, la historia de Sabrina resonó en los medios de comunicación, alcanzando rápidamente una gran adhesión y apoyo social.

Poco tiempo después de esta resolución, el Congreso de la Nación Argentina sancionó la Ley 27.552 de lucha contra la enfermedad de fibrosis quística de páncreas o mucoviscidosis. Ley que permitió al Estado Nacional dar un paso firme en la protección de los derechos humanos fundamentales de un grupo vulnerable de nuestra sociedad.

Adicionalmente, para ese tiempo, Argentina estaba comenzando a sentir el peso de las primeras medidas del aislamiento social preventivo y obligatorio en torno a la pandemia mundial ocasionada por el COVID-19. 


\begin{abstract}
The justice of the province of Córdoba granted the request for a precautionary measure authorizing $100 \%$ of the coverage of the drug TRIKAFTA for the treatment of cystic fibrosis. It is about a young woman, Sabrina Monteverde, who suffers from this rare disease and who, due to the serious state of health she is experiencing, had to initiate a protection action against Apross.

Although it is not the first case of a patient requiring the aforementioned medication, Sabrina's story resonated in the media, quickly reaching great adhesion and social support.

Shortly after this resolution, the Congress of the Argentine Nation sanctioned Law 27,552 to combat the disease of cystic fibrosis of the pancreas or mucoviscidosis. Law that enters the National State to take a firm step in the protection of the fundamental human rights of a vulnerable group of our society.

In addition, by that time, Argentina was beginning to feel the weight of the first measures of preventive and mandatory social isolation around the global pandemic, caused by COVID-19.
\end{abstract}

PALABRAS CLAVE: Fibrosis quística; Derecho a la salud; Acción de amparo; Política pública sanitaria; Repercusión mediática.

KEY WORDS: Cystic fibrosis; Right to health; Amparo action; Public health policy; Media impact.

\title{
I. Introducción
}

Sabrina Monteverde, una conocida joven cordobesa, padece una enfermedad genética, hereditaria, autosómica recesiva con afectación multiorgánica, de curso crónico y evolutivo, que requiere de tratamiento permanente. Estamos hablando de fibrosis quística.

Para el año 2020, su cuadro de salud era preocupante. A pesar de los tratamientos médicos y cuidados diarios, debió ser internada en reiteradas ocasiones y sus estudios médicos daban cuenta de un importante deterioro pulmonar y pancreático. Peor aún, era candidata a evaluación de pre trasplante bipulmonar dado que su función pulmonar había descendido considerablemente en el último tiempo.

Este contexto, llevó a su medica tratante a prescribir un tratamiento con el fármaco TRIKAFTA (Elexacaftor/Tezacaftor/lvacaftor), entendiendo que la combinación de medicamentos que contiene permitiría mejorar su función pulmonar, procurando evitar el trasplante y mejorar su calidad de vida. Asimismo, estimó que no existía otra alternativa terapéutica similar en el país o que ofrezca los beneficios que proporcionaría TRIKAFTA. Sabrina contaba con la cobertura médica de la Administración Provincial del Seguro de Salud, Apross, por lo que, mediante el trámite de Empadronamiento de Pacientes Crónicos solicitó la cobertura integral de dicha medicación.

Por su parte, la obra social demandada se opuso a la solicitud alegando que dicho tratamiento no se encontraba dentro de sus prestaciones vigentes $y$, por otro lado, que tampoco contaba con la aprobación de la Administración Nacional de Medicamentos, Alimentos y Tecnología Médica, ANMAT.

Frente a la negativa de Apross y las circunstancias particulares del diagnóstico, Sabrina y 
su familia iniciaron acción de amparo contra la obra social a fin de que brinden la cobertura integral solicitada.

El día 03 de julio del 2020, la Cámara Contencioso Administrativa de 2da Nominación del Poder Judicial de Córdoba, dictó una sentencia favorable a la familia Monteverde, pues le hizo lugar a la medida cautelar para la cobertura de la medicación. Para resolver en este sentido, la Cámara tuvo en cuenta no sólo la prescripción y justificación brindada por la médica tratante, sino además informes de evidencia científica de la misma y sus efectos favorables. Incluso, ANMAT había autorizado la importación del medicamento para uso compasivo.

El tribunal referenció al derecho a la vida como el primer derecho natural de la persona humana y citó normas de derecho internacional, nacional y locales referidas al derecho a la salud. Asimismo, resaltó el deber del Estado de llevar a cabo acciones positivas en miras a garantizar los derechos individuales con el objetivo de que no se tornen ilusorios.

Hasta entonces, diferentes tribunales se habían expedido de manera favorable para la cobertura de TRIKAFTA para otros pacientes, pero esta situación no podía resolverse mediante medidas cautelares dictadas por jueces para cada caso concreto, existía la necesidad de una política pública sanitaria en la materia aplicable a todo el país. Sobre este punto, el tribunal del caso exhortó a las autoridades sanitarias nacionales y provinciales a promover una legislación específica de protección de pacientes con fibrosis quística. ${ }^{2}$

La Cámara Contenciosa Administrativa (2020) al resolver expresó que "no se trata de resolver judicialmente el caso de Sabrina, sino que el caso de Sabrina debe tener la virtualidad para motorizar y exhortar a las acciones positivas de los órganos gubernamentales, especialmente nacional, para brindar accesibilidad en la cobertura, con criterios de justicia distributiva y solidaridad."

Paralelamente a la judicialización de esta solicitud, Sabrina utilizó las redes sociales para contar su caso. En efecto, publicó un video en las redes sociales donde contó cómo son sus días, sus padecimientos y la necesidad de contar con TRIKAFTA para mejorar su calidad de vida. El caso de Sabrina no sólo fue contado por los noticieros locales, sino que su video se difundió por diferentes redes y alcanzó millones de reproducciones. Sabrina rápidamente se convirtió en un ícono local de lucha contra la fibrosis quística.

Tal es así que, pocos meses después, el 11 de agosto de 2020 se sancionó la Ley Nacional N. ${ }^{\circ} 27.552$ de lucha contra la enfermedad de fibrosis quística de páncreas o mucoviscidosis.

\section{El derecho a la salud como derecho humano fundamental}

La Organización Mundial de la Salud, en su Carta Constitutiva, expresa que "La salud es un estado de completo bienestar físico, mental y social, y no solamente la ausencia de afecciones o enfermedades"3. Así concebida, la salud es catalogada como un derecho humano fundamental "sin distinción de raza, religión, ideología política o condición económica o social."4

\footnotetext{
2 Sociedad Argentina de Pediatría, Subcomisiones, Comités y Grupos de Trabajo (2008): Consenso Nacional de Fibrosis Quística (https://www.sap.org.ar/docs/ profesionales/consensos/v106n5a12e.pdf) (fecha de consulta: 01 de mayo de 2021).

3 Organización Mundial de la Salud (2006): Constitución de la Organización Mundial de la Salud. (https://www.who.int/governance/eb/who_constitution_ sp.pdf?ua=1) (Fecha de consulta: 15 de julio de 2021).

4 Organización Mundial de la Salud (2006): Op. Cit. (Nota N²).
} 
En el sistema normativo argentino, hasta antes de la reforma de 1994, el derecho a la salud encontraba recepción en el artículo 33 de la Constitución Nacional como derecho no enumerado. A partir de la citada reforma, mediante la incorporación de Tratados Internacionales de Derechos Humanos a la Carta Magna (artículo 75, inciso 22), se les otorgó jerarquía supralegal y constitucional a los derechos en ellos reconocidos. Podemos mencionar el art. 12, inc. 1 del Pacto Internacional de Derechos Económicos, Sociales y Culturales, el art. 6. 1. del Pacto Internacional de Derechos Civiles y Políticos, los arts. 4.1. y 5.1. de la Convención Americana sobre Derechos Humanos, el art. 3 de la Declaración Universal de Derechos Humanos y el art. 11 de la Declaración Americana de Derechos y Deberes del Hombre.

A modo de ejemplo, el artículo 11 de la Declaración Americana de Derechos y Deberes del Hombre de 1948, establece que "toda persona tiene derecho a que su salud sea preservada por medidas sanitarias y sociales, relativas a la alimentación, el vestido, la vivienda y la asistencia médica, correspondientes al nivel que permitan los recursos públicos y los de la comunidad." ${ }^{5}$

Es indiscutible el reconocimiento legal, supralegal y constitucional que goza el derecho a la salud. Pues bien, la salud -como la vida- son indispensables para el ejercicio de otros derechos y el pleno goce de la autonomía personal.

\section{Protección del derecho a la salud 1. Amparo de salud}

Partiendo de la idea de que la preservación de la salud integra el derecho a la vida y que, tanto la salud como la vida son indispensables para el ejercicio de otros derechos y la realización de proyectos personales, estamos en condiciones de afirmar que el derecho a la salud genera obligaciones sobre las autoridades públicas para asegurar su plena vigencia.

En concreto, siempre que se reconoce un derecho es necesario establecer los mecanismos idóneos para asegurar su efectivo disfrute, de lo contrario sólo serían manifestaciones abstractas.

Ahora bien, en materia sanitaria el factor tiempo es fundamental a la hora de procurar una solución justa. Así, "el acceso en tiempo y forma a la atención de la salud materializa este derecho humano fundamental reconocido a nivel constitucional y convencional." 6

De allí que, nuestra legislación prevé como mecanismo idóneo para la protección de este derecho, la acción de amparo como un procedimiento rápido y simplificado. Este proceso tiene reconocimiento constitucional desde la última reforma de 1994 y se encuentra regulado por la Ley 16.986.

Así, ante demoras o incumplimiento de prestaciones de salud, el amparo se erige como la medida más eficaz para proteger los derechos del paciente, dando lugar a que un juez se expida sobre el asunto, evitando que el paso del tiempo cause perjuicios irreparables en la salud de las personas.

5 INFOLeg, Información Legislativa y Documental (2020): Declaración Americana de Derechos y Deberes del Hombre (http://www.infoleg.gob.ar/?page id=1000) (Fecha de consulta: 15 de julio de 2021).

6 TANZI, Silvia Y y PAPILLU, Juan M (2018): Juicio de amparo en salud, Análisis bajo el Código Civil y Comercial de la Nación, Buenos Aires, Ed. Hammurabi, p. 15. 
En el caso que analizamos, el agravamiento del estado de salud de Sabrina exigía de un procedimiento rápido y expedito que diera respuesta a su petición. Fue por ello que, interpusieron una acción de amparo contra Apross, solicitando la cobertura de la medicación prescripta.

En conclusión "[q]ueda claro que existe un amplio reconocimiento del derecho a la salud y, por ello cabe recordar la doctrina de" la Corte Suprema de Justicia de la Nación, por cuanto señala "que donde hay un derecho debe haber un remedio legal para hacerlo valer toda vez que sea desconocido, principio del que ha nacido la acción de amparo, pues las garantías constitucionales existen y protegen a los individuos por el solo hecho de estar en la Constitución e independientemente de sus leyes reglamentarias (....".7

\section{Obligaciones del Estado Nacional}

Así como las personas tienen el derecho de acceder a las prestaciones de salud, como contrapartida el Estado Nacional no sólo debe asegurar una tutela judicial efectiva -como sucedió en el caso de Sabrina-, sino que además debe abstenerse de causar daños, como así también debe llevar a cabo acciones positivas tendientes a organizar y regular el sistema de salud en Argentina.

La sentencia que estudiamos nos conduce a hacer hincapié en las acciones positivas que recaen en las autoridades, ya sea a través de la creación y puesta a disposición de servicios públicos de salud, como la regulación y control de los mismos.

Respecto al primer punto, es preciso recordar los estándares para el derecho a la salud establecidos por el Comité de Derechos Económicos, Sociales y Culturales, a través de la Observación General N¹48, del año 2020. Los estándares son: disponibilidad, accesibilidad, aceptabilidad y calidad.

En pocas palabras, los Estados partes deben crear infraestructuras a disposición del servicio de salud en todo su territorio, que deben ser accesibles a todas las personas sin discriminación, garantizando una accesibilidad tanto física como económica, como así también a la información pertinente sobre los problemas de salud. A la vez, deben estar dispuestas conforme a la cultura y las practicas sociales locales y gozar de calidad científica y médica apropiada.

En relación al segundo punto, en cuanto la organización y regulación del sistema de salud adquiere relevancia el rol del poder legislativo en su tarea de deliberar y sancionar leyes que tengan en miras el bien común de todos los habitantes.

Tal es así que, oportunamente se han dictado numerosas leyes en la materia. Específicamente, para el año 2020 y en lo que se refiere a la fibrosis quística que padece Sabrina, podemos mencionar como legislación aplicable al caso, la Ley N. ${ }^{\circ} 26.378$ que aprobó la Convención sobre los Derechos de las Personas con Discapacidad y la Ley N. ${ }^{\circ} 26.689$ de Enfermedades Poco Frecuentes.

Sin embargo, estas disposiciones no eran suficientes para garantizar la tutela jurídica

\footnotetext{
7 TANZI, Silvia Y y PAPILLU, Juan M (2018): Ob. Cit., p. 83.

8 Consejo Económico y Social (2000): Observación General Nº14 (https://www.acnur.org/fileadmin/Documentos/BDL/2001/1451.pdf) (Fecha de consulta: 15 de julio de 2021).
} 
de los derechos que asisten a quienes padecen esa enfermedad. Por ello, al momento de resolver el caso de la joven Monteverde, el tribunal se expresó sobre la necesidad de "exhortar" a las autoridades públicas, nacionales y provinciales para que "expresen y promuevan activamente la imperiosa necesidad de contar con una legislación específica, esto es la Ley sobre protección de los pacientes con fibrosis quística".

Asimismo, reconoció que, si bien es posible revertir la situación de los pacientes mediante resoluciones judiciales en cada caso concreto, dando lugar a los pedidos de cobertura médica, esto no debe ser de ese modo, sino que es preciso "una política pública de concertación federal" aplicable a todo el país.

Poco tiempo después de que Sabrina obtuviera una resolución favorable, el Congreso de la Nación Argentina sancionó la Ley N. ${ }^{\circ} 27.552$ de lucha contra la enfermedad de fibrosis quística de páncreas o mucoviscidosis. ${ }^{9}$

Esta normativa establece el régimen legal de protección, atención de salud, trabajo, educación, rehabilitación, seguridad social y prevención, para que las personas con esta enfermedad alcancen su desarrollo e inclusión social, económica y cultural. Además, incorpora a la fibrosis quística como enfermedad priorizada dentro del Programa Nacional de Enfermedades Poco Frecuentes.

Asimismo, promueve una protección integral, no solo a nivel diagnóstico y tratamiento médico desde el nacimiento, en todas sus dimensiones para lograr su adecuada integración social. Al mismo tiempo, dispone del 100\% de la cobertura de medicamentos, tratamientos, estudios y cualquier práctica médica que se relacionen o deriven de esta patología.

Por otro lado, según su reglamentación aquellas personas que tengan un diagnóstico confirmado de esta enfermedad, podrán solicitar el Certificado Único de Discapacidad -CUD-.

La sanción de esta ley permite velar por la vigencia real y efectiva de los derechos de estas personas, pertenecientes a un grupo vulnerable de nuestra sociedad, que ya no dependerán de la decisión de un juez para cada caso concreto, sino que sus derechos ya están plasmados expresamente en la ley.

\section{Contexto y repercusión mediática del caso}

A comienzos del año 2020, el mundo entero empezaba, poco a poco, a sacudirse por los efectos de lo que pronto se convertiría en una pandemia mundial. La rápida propagación del virus COVID-19, el creciente número de muertes y la escasa información sobre su prevención y tratamiento, obligaron a los Estados a tomar diferentes medidas de aislamiento y protección.

En Argentina se dispuso de un Aislamiento Social Preventivo y Obligatorio, que en líneas generales implicaba que toda actividad que no fuera un "servicio esencial" quedaba suspendida, prohibiéndose la circulación de las personas, salvo excepciones especialmente previstas por la reglamentación.

En este marco, el servicio de justicia había entrado en "feria", quedando una guardia mí-

9 INFOLeg, Información Legislativa (2021): Ley de lucha contra la enfermedad de fibrosis quística de páncreas o mucoviscidosis, Ley 27.552 (http://servicios. infoleg.gob.ar/infolegInternet/anexos/340000-344999/340915/norma.htm) (Fecha de consulta: 10 de mayo de 2021). 
nima que sólo actuaba en casos urgentes. Para ese entonces, Sabrina presentó ante los tribunales su acción de amparo para la obtención de la medicación TRIKAFTA.

Antes de que la justicia resolviera su caso, la historia de Sabrina cobró importancia mediática a través de la difusión de una grabación en la que ella, en primera persona, contaba sobre el padecimiento de su enfermedad.

La historia no sólo fue contada por los noticieros locales, sino que su video se volvió viral y en poco tiempo alcanzó más de nueve millones de reproducciones. La joven envió un mensaje directo a la sociedad y a las autoridades, quería ser escuchada y generar concientización sobre la fibrosis quística.

Las repercusiones del uso de las redes sociales fueron notorias. No sólo generó movilización y apoyo social por su relato, sino que además puso en tema de debate la enfermedad y los tiempos de la justicia. Sabrina (2020) manifestó “mi cuerpo ya no entiende de tiempos, estoy peleando por mi vida", "un fármaco por el cual estoy peleando judicialmente desde hace un par de meses, pero lamentablemente está todo muy frenado", "entiendo que hay tiempos, pero la fibrosis quística no entiende de tiempos"10.

Casi de inmediato, la Cámara Contenciosa Administrativa que debía resolver su petición, no sólo dictó una sentencia favorable, ordenando la cobertura al 100\% de la medicación requerida, sino que además exhortó a las autoridades competentes para resolver definitivamente el problema de las personas en su misma situación.

Posteriormente, se logró la conquista de la lucha de los pacientes de fibrosis quística, mediante la sanción de la Ley mencionada en el apartado anterior, ley N. ${ }^{\circ} 27.552$.

Sobre este punto, es importante recalcar la presencia cada vez más protagónica de los medios masivos de comunicación digitales y la innovación de internet en cada ámbito de la vida cotidiana. En este marco, las redes sociales "[c]onstituyen verdaderos espacios o vehículos de comunicación, expresión popular y poder (...)"111.

Las redes permiten, a quien desea comunicar algo, narrar en primera persona y ser la fuente informativa. Los mensajes que se transmiten por este canal llegan a miles de personas, en tiempo real y con efecto viral. Y es lo que sucedió en este caso.

\section{Conclusiones}

En primer lugar, garantizar el goce del derecho a la salud permite procurar una mejor calidad de vida en cualquier aspecto de la persona. En el caso que nos compete, Sabrina precisaba continuar sus estudios universitarios -entre otras cuestiones-, pero sus condiciones de vida no lo permitían, obstaculizándose el goce y disfrute del derecho a la educación.

De allí que, de todo lo expuesto hasta aquí es fundamental no perder de vista que el derecho a la salud es un derecho humano fundamental y que su preservación integra el derecho a la vida. Esto tiene su razón de ser, por cuanto no es posible el ejercicio pleno

10 MONTEVERDE, Sabrina (02 de julio de 2020): APROSS debe cubrir TRIKAFTA. El cuerpo no espera (https://www.instagram.com/tv/CCHwbSugVl2/?utm_ source=ig_web_copy_link)

11 TOMEO, Fernando (2014): Redes sociales y tecnologías 2.0, Buenos Aires - Bogotá, Ed. Astrea, p. 45 
de otros derechos sin contar antes con vida y salud.

En segundo lugar, la historia de Sabrina es la historia de muchas personas que sufren afectaciones en su salud, en mayor o menor medida. Pero su caso traspaso los límites de tiempo y espacio gracias al poder de los medios masivos de comunicación.

La joven acudió a las redes sociales para hacerse escuchar y no sólo lo logró, sino que además obtuvo un gran apoyo social que provocó cierta presión sobre las autoridades. Tal es así, que en muy poco tiempo obtuvo la respuesta judicial que estaba buscando desde hacía un tiempo ya.

La repercusión mediática y la difusión masiva puso de manifiesto la fuerza de las nuevas tecnologías de la comunicación e información, que deben ser utilizadas de manera consciente y prudente.

Por último, todos aquellos casos que llegaron a judicializarse en búsqueda de una cobertura médica integral para el tratamiento de la fibrosis quística y el resonante caso de Sabrina, que sacudió a los medios, no hicieron más que poner en evidencia la necesidad de una normativa específica sobre esta materia.

La sanción de la Ley 27.552 que declaró de interés nacional la lucha contra esta enfermedad es una conquista para quienes la padecen y su familia.

Este desenlace afortunado deja en evidencia que el derecho es una herramienta elemental y que gracias a él "existe la posibilidad de cambiar las normas juntando la fuerza necesaria, entonces nos entusiasmamos, porque se nos abre una puerta, al ver que el derecho tiene potencialidad transformadora."12

\section{REFERENCIAS BIBLIOGRÁFICAS}

- Consejo Económico y Social (2000): Observación General N¹4 (https://www.acnur.org/ fileadmin/Documentos/BDL/2001/1451.pdf) (Fecha de consulta: 15 de julio de 2021).

- INFOLeg, Información Legislativa y Documental (2020): Declaración Americana de Derechos y Deberes del Hombre (http://www.infoleg.gob.ar/?page_id=1000) (Fecha de consulta: 15 de julio de 2021).

- INFOLeg, Información Legislativa (2021): Ley de lucha contra la enfermedad de fibrosis quística de páncreas o mucoviscidosis, Ley 27.552 (http://servicios.infoleg.gob.ar/infolegInternet/anexos/340000-344999/340915/norma.htm) (Fecha de consulta: 10 de mayo de 2021).

- MONTEVERDE, Sabrina (02 de julio de 2020): APROSS debe cubrir TRIKAFTA. El cuerpo no espera (https://www.instagram.com/tv/CCHwbSugVI2/?utm_source=ig_web_copy_link). - Organización Mundial de la Salud (2006): Constitución de la Organización Mundial de la Salud. (https://www.who.int/governance/eb/who_constitution_sp.pdf?ua=1) (Fecha de consulta: 15 de julio de 2021). 
- Profesorado en Ciencias Jurídicas (2020): Nociones sobre las perspectivas jurídicas, Ficha de catedra, Córdoba, Universidad Nacional de Córdoba.

- Sociedad Argentina de Pediatría, Subcomisiones, Comités y Grupos de Trabajo (2008): Consenso Nacional de Fibrosis Quística (https://www.sap.org.ar/docs/profesionales/consensos/v106n5a12e.pdf) (fecha de consulta: 01 de mayo de 2021).

- TANZI, Silvia Y. y PAPILLU, Juan M. (2018): Juicio de amparo en salud, Análisis bajo el Código Civil y Comercial de la Nación, Buenos Aires, Ed. Hammurabi.

- TOMEO, Fernando (2014): Redes sociales y tecnologías 2.0, Buenos Aires - Bogotá, Ed. Astrea. 